\title{
Immigrant Children's Bodily Engagement in Accessing Their Lived Experiences of Immigration: Creating Poly-Media ${ }^{1}$ Descriptive Texts
}

\author{
Anna Kirova, University of Alberta \\ Email: anna.kirova@ualberta.ca \\ Michael Emme, University of Victoria \\ Email: memme@uvic.ca
}

\section{Abstract}

In this paper, we explore the role of the lived body in meaningful understanding beyond linguistic conceptualization in phenomenologically oriented inquiries. In this exploration we consider the role of visuality (i.e., still photography) and enactment (i.e., tableau) as possibilities for accessing meaning beyond language-bound descriptions of the phenomenon of moving childhoods - that is, children's lived experiences of immigration. We suggest that immigration is an experience that interrupts the familiarity of the lifeworld, and thus brings immigrant children's awareness of their bodies to a conscious level. We ask: What methods of inquiry can be used to access more directly the "embodied understanding" and, in particular, the lifeworlds of immigrant children as they leave the familiar "home world" and enter the "alien world" of a new school? In addressing this question, we focus on one aspect of phenomenological inquirygathering experiential accounts, or lived experience descriptions, in investigating childhood phenomena-which presents a particular challenge to researchers working with young children. We present an example of a method that bridges hermeneutic phenomenology and arts-based research methodology (i.e., fotonovela) developed specifically to engage immigrant children bodily in accessing their lived experiences of their first day of school in the host country, and in the development of a polymedia text showing these experiences. We believe that the example demonstrates how fotonovela facilitates immigrant children's recollection of and reflection on their experience of being at the door of a new classroom. Moreover, the production of visual texts, when shared with or read by others, has an evocative power similar to that of a phenomenological text. Thus, we argue, fotonovela is a particularly suitable method for engaging children in developing polymedia descriptive texts about their lived experiences. 


\section{Introduction}

The phenomenological understanding of the body, which Merleau-Ponty (1963) calls the "living envelope of our actions" (p. 188), is central to the human lifeworld, and thus central to phenomenological method. For him, the body and behavior are bearers of meaning that is known immediately as well as reflectively by the body. "The body is the basis for reflection and there is no possibility of pure reflection" (Merleau-Ponty, 1962, p. 62). Shapiro (1985) points out that the study of language and the development of linguistic methods in the past few decades have influenced all fields including phenomenology and have resulted in an "assertion of the primary and pervasive influence of language in experience" (p. xiv). He argues against the exclusive use of language-centered reflection as the core of phenomenological method of inquiry. Instead, his work attempts to show how an "investigator can avail himself or herself of reflective modes and moves that are largely explicable in terms of a phenomenology of the body" (p. xvii), which he defines as the embodiment of our consciousness.

In this article, we too acknowledge that reflective practices grounded predominantly in language present phenomenology with a dilemma; human phenomena are lived through our bodies, but are typically described through language, which in turn is supposed to invoke an embodied response as part of the process of understanding. We explore the role of the lived body in meaningful understanding beyond linguistic conceptualization in phenomenologically oriented inquiries. In this exploration, we consider the role of visuality (i.e., still photography) and enactment (i.e., tableau) as possibilities for accessing meaning beyond language-bound descriptions of the phenomenon of moving childhoods - that is, children's lived experiences of immigration. We present an example of a method that bridges hermeneutic phenomenology and arts-based research methodology (i.e., fotonovela), which was developed specifically to engage immigrant children bodily in accessing their lived experiences of their first day of school in the host country and in the development of a multimedia text showing these experiences.

We want to stress here that this fotonovela method represents only one phase of phenomenological inquiry-gathering experiential accounts or lived experience descriptions in investigating childhood phenomena. The focus on this phase of a phenomenologically oriented inquiry is based on our work with young children over the years. This work has shown that commonly used methods of collecting experiential accounts based on oral or written descriptions of lived experiences is limiting as children rarely produce "thick descriptions" of their lived experiences if they rely solely on language to do so. As van Manen (1994) puts it, "Especially with young children this [writing] is a handicap. Often educational researchers like to ask children to write about their experiences or to keep a log or diary, and they end up being somewhat disappointed with the material they were able to generate from children this way" (p. 64). Although in general "it is easier to talk than to write about personal experience" (p. 67), this is not the case for children who are still learning the language of their host country, and with whom researchers do not share a common language. We argue that fotonovela is a particularly suitable method for engaging children in developing polymedia descriptive texts about their lived experiences. 


\section{Situating the Question in the Body}

Of particular interest and relevance to the method of inquiry presented here is Shapiro's (1985) explanation of how any situation invites a person to take a certain course of action, to move in a certain way with respect to it (e.g., playing a game, going through a door, using a computer, etc.) that also has a bodily aspect. This move does not mean that a person is always aware in an analytical or language-based way of how a situation requires a bodily response or what this bodily response may look like. Quite the opposite, it is my body that is always with me; I am in it first and then in the world of objects around me that I may or may not know, but could encounter through my body. Gendlin (1997a) says, "The body knows the situation directly.... A living body knows its environment by being in it” (p. 27). This is the taken-for-granted level at which humans act and experience before attaching language to their actions or experiences.

Yet some life experiences change the pre-reflective, lived familiarity with the world or the potential for action that one's body had in a known world and bring the experience of the body into the realm of consciousness. To use Shapiro's (1985) words, some situations "invite a person" to take a certain course of action with which he or she is not familiar so the body's movement is changed with effort, and thus involves some level of nonverbal conscious participation. In this article we argue that immigration is one such experience-an experience that interrupts the familiarity of the lifeworld that we associate with the feelings of "normal" in the "home-world" (Steinbock, 1995) and brings to the forefront the "abnormality" of the "alienworld," the unfamiliar or even the phenomenon of nonrecognition. We argue that this experience brings immigrant children's awareness of their bodies to a conscious level as they encounter the impossibility of trusting the outcomes of their otherwise familiar actions. These actions and unexpected outcomes might include, for example, the experience of approaching others and expecting them to join in an ongoing game, or simply speaking of achieving a particular goal. By not being able to count on the outcome of acts and of speaking in these kinds of situations we are referring not only to the fact that immigrant children initially speak a language that no one outside the home understands, resulting in incomprehension or misapprehension. Rather, we refer also to the embodied, performative nature of such communication-and the fact that such embodied performances, despite their sometimes self-evident significance, are also put into question. We fully agree with Gendlin (1997b) that speaking is a "special case of body interaction” (p. 28), and that the interactional body provides a crucial grounding to language. A bodily sensed situation in relation to words "gives the words a new life" (Gendlin, 1997a, p. 8) by elevating meaning from the two-dimensionality of code and narrative to the multiple dimensions of embodied experience lived through time and space.

The following is a personal experience that illustrates the above statements about the act of speaking and the role of embodied language in understanding:

As an immigrant and adult learner of English, I am seen by many as an example of success. Not only do I make myself understood, but I am also a proficient reader and writer of English. I give public presentations and lecture at the university. Yet upon receiving a set of student evaluations a few years ago, I became aware of a strange phenomenon: I was profoundly ineffective in communicating my true intentions in my interactions with some of my students in class. It became clear to me that it was not what I said that offended the students, but how I said it. The What of the English language had to do with the 
accessibility of the factual meaning of the words, which regardless of my accent, was not perceived as problematic by the students. The How of my English language, that is, my tone of voice, speech rhythm, accompanying gestures, proximity to the students, movement around the room, pauses after a statement, or facial expression while listening and responding to questions, however, was not consistent with the conventions of the English language that the students expected. Thus the intended meaning of my words was lost.

When I was in the beginning stage of learning English, speaking was hard work: I first composed a simple sentence in my mother tongue and then painfully rushed though my "stored" vocabulary in English to find the words that were most appropriate or closest in meaning to use in the sentence that I held in my mind. It seemed like it took a lifetime to be able to do this, yet people were patient, polite, understanding, and accommodating. No one laughed at me. On the contrary, people filled in my half sentences trying hard to make sense of my desperate gesturing; they smiled or nodded enthusiastically and supportively. With time and practice, composing sentences became less work, and I was able to express myself with less effort. Paradoxically, however, the more fluent my spoken language became, the less accurately some native speakers understood me. I was faced with a contradiction that seemed irresolvable: my increased facility with the spoken language increased my difficulty in conveying the intended meaning. In other words, I was speaking a language fluently that I did not embody fluently. I realized that in the how of my spoken English, I remained a Bulgarian.

From this moment on, I became painfully aware of my body every time I spoke English, which is now more than 90 per cent of the day. I am trying to "see" myself speaking and trying to match my gestures and my tone of voice to what I have observed native speakers doing when they express meaning similar to what I wish to express. It is hard work again, and I am not sure that it works any better. I am always unsure of the outcome of my spoken communication in English. People who have seen me speak my mother tongue have commented that I am a "different person" when I speak it. And I certainly am. I now think mostly in English and have to spend some time thinking what words to use in Bulgarian when I talk to my mother, for example, but I do not have to think about not being Bulgarianenough in my body language. My body is in my native language as much as the language is in my body. (Emme, Kirova, Kamau, \& Kosanovich, 2006, pp.161162)

We wonder if immigrant children have similar experiences of the how and what of the language they learn in their host country. The following recollection of a childhood experience provided by a foreign-born graduate student who was "angry at her mouth" for not being able to speak English like her classmates is a powerful example that children, too, are not only aware of the what but also the how of the new language.

I remember clearly spending long hours in our bathroom looking at myself in the mirror while trying to say the few English words I knew then. I even used my fingers to move my mouth in a different direction from the one it would normally take when forming the sounds with the hope that this time the word would come 
out right. I did not care that I looked ridiculous with my fingers in my mouth; the only thing I wanted was to be able to say the words like everyone else. At the beginning my mother was not worried, but when I started spending way too much time in the bathroom and used to come out of it with my mouth bright red and my eyes filled with tears, she stepped in. I was no longer allowed to close the door when I was in there. I was angry at myself, no, I was angry at my mouth and at my mother. (Personal communication, 2004)

A description provided by a child when he was 5 years old about his experience of learning English as a second language in the first few months after immigrating, shows clearly that young children are aware of their bodies as they speak another/new language, not only upon reflection on their childhood experiences, but also close to the time when the experience was lived.

It was like I couldn't control what was going to come out of my mouth. It was in my head, I could hear the appropriate sounds but when I opened my mouth, the sounds were very different from the ones I thought they would be. I was really embarrassed and didn't want to talk at all. It was like I couldn't trust myself anymore. I felt so stupid. (Kirova, 2001, p. 263)

Based on the above descriptions gathered as part of previous studies, we wonder, in the context of this study, what other circumstances make immigrant children acutely aware of their bodies. What situations invite bodily responses that require conscious efforts? A close examination of the above descriptions also made us aware of the difference in the "think-ness" of descriptions provided by adults and by young children. From a methodological point of view, then, we began to wonder how these bodily experiences can be understood. The main question we explore in this paper is: What methods of inquiry can be used to access more directly the "embodied understanding" and, in particular, the lifeworlds of immigrant children as they leave the familiar "home world" and enter the "alien world" of a new school?

In exploring this question, we build on Gadamer's (1993) notion of understanding as the linguistic "happening" of tradition - that is, the embodied knowing of home, body, community, and meaning, but also a happening that exceeds tradition and lives it forward. We also build on Heidegger's (cited in Todres, 2007) understanding of the relationship between language and being as mysterious for "the 'unsaid' lives always exceedingly as that which the said is about" (p. 19); being in the world always transcends its forms and intrinsically exceeds linguistic capture. Heidegger's “unsaid” is similar to Gendlin's (1997a) “mores”-that is, our bodily relational understandings exceed any precisely formulated, languaged, or other patterned ways of describing it. Thus as Gendlin (1997b) puts it, "in an embodied way, understanding is rather a procedure which includes the invitation to experience more” (p. 1).

\section{Embodied Inquiry and Phenomenology}

The phenomenological method aims at establishing "what is typical of the phenomenon and expressing such typicality in an insightful and integrated manner" (Todres, 2007, p. 8). Based on individual experiences, phenomenology strives to describe "how the elements of a phenomenon function constitutively; how they are interrelated to form unity of the experience” (Reed, 1987, 
p. 102). This level of generality is known as structure, which once achieved is in danger of losing the individuality and particularity of each experience. The tension between the particular and the general is ongoing in phenomenological inquiry. How this tension is resolved in phenomenological descriptions affects a reader's sense of the phenomenon and, thus, of his or her understanding of it based on the description. The notion that there is always more to the experience than what is captured in its language-based description is central to the role of the lived body in understanding a phenomenon.

Merleau-Ponty's (1962) work on the phenomenology of perception is explicit in describing how the human body is intimately present not only in all human experiences, but also in any act of understanding the structure of experiences that "are lived rather than known and therefore can never be apprehended passively; but only by living them, assuming them and discovering their immanent significance” (p. 158).

In the preface of his book Bodily Reflective Modes: A Phenomenological Method for Psychology, Shapiro (1985) gives a powerful example of the experience of watching a mime (in this case, the now well-known French mime Marcel Marceau), whose portrayal of a prisoner behind a prison wall evoked comprehension of the experience based on one's bodily sense of the phenomenon performed on stage. Based on the experience of seeing Marcel Marceau's performances, Shapiro suggests that our bodily knowledge of a phenomenon enables us virtually to enact a particular phenomenon. In other words, it allows us to create the space of that experience, and the relationships and world implied in it even without seeing it bodily performed. He argues that "enactment is a critical step in the explication of any given phenomenon" (p. xviii). The importance of "re-enact-ment” in understanding is also pointed by Dilthey (as cited in Todres, 2007) for whom to understand any experience, either our own or others', is to be able "to bring it into light of one's own possibilities-and thus to re-enact it" (p. 10). Thus, the ultimate task of phenomenologically oriented inquirers is to evoke the presence of a lived experience. The question faced by researchers becomes, if there is always more to a phenomenon than words can capture, how else can we seek to show its presence?

We note here that in doing phenomenologically oriented research, we looked for concrete ways to apply Dilthey’s (Todres, 2007) notion of “bringing to light” one’s (bodily) possibilities as well as Dilthey's and Shapiro's (1985) notions of “re-enact-ing” these possibilities as a way of understanding a phenomenon. Applying these notions allowed us to attempt to show the more of a phenomenon-more than children, and sometimes even adults, could describe in words. In the following section, we explore the controversy surrounding the use of photography-the Greek combination of the two words, photos (light) and graphein (to draw) (Chan-fai, 2004) - in phenomenologically oriented research as a means of capturing the more of a phenomenon. We revisit the notion of "en-act-ment" below, by providing an example of our own work in which we used a technique borrowed from performative research — that is, tableau — to engage children in enacting their lived experiences of their first day in school.

As a performative art form, tableau is a non-language-dependent medium that "transcends the customary limits of discursive language, making coherent the knowledge and the understanding that students may not be able, at first, to express in spoken language but that, once embodied in movement, can be translated into spoken and written language” (Salvio, 1990, p. 272). In the study described here, children used their bodies - through hand gesture, facial expression, body posture, and body positioning relative to others (Wilson, 2003) - to show emotion and action. Bruner (1986) identifies action as one of the two landscapes of story. Narrative, he says "deals with the vicissitudes of human intentions" (p. 16), and to understand these intentions means to 
understand life. Through the use of performative gestures, which build on the natural gestures used in communication (Wilson, 2003), as well as through culturally established gestures, the children showed a range of emotions related to situations involving peers. In drama, as in play, children had to negotiate with each other to create a single vision of the meaning of a gesture or any other visual sign- "this stands for that"-in the context of the visual narrative. As an effective means for helping children create meaning and deepen their understanding of the peer relationship aspect of their school life, the process of playful dramatization was invaluable. It allowed children to be "launched on a voyage toward a truth beyond mere facts" (Wagner, 1998, p. 33).

\section{Photography and Phenomenology}

Ziller and Smith (1977) present a phenomenological approach that is extended to the medium of photography. They define the photograph as "a non-verbal projective technique" (p. 177), and a "unique medium which frees subject from some of the constraints of language" (p. 182), but they also acknowledge that there are similarities between verbal reports and photographs as both are "meditational" (p. 172). They point to advantages inherent in the use of photography as opposed to verbal self-reports as a phenomenological technique. "The most significant perhaps, is that the camera documents the subject's perceptual orientation with a minimum of training and without the disadvantages of the usual verbal report techniques. Thus the 'training' does not obtrude between the subject and [his] report of the phenomenon” (p. 173).

Not surprisingly, Shapiro dismisses the notion of the unproblematic objectivity of photography in phenomenological investigations. In this sense, according to Shapiro (1985), the photograph can only provide the researcher with “"pseudo-presence' of the thing itself” (p. 27). If read naturalistically, photographs can be seen as evidence for the existence of objects as they really are. Shapiro sees no value in using photography in phenomenological research. He states:

What might appear at first glance to provide a "technology for phenomenology" (Ziller \& Smith, 1977, pp. 172-182), a way of returning to and staying with a version of the thing itself by carrying away its direct impress, is yet another brand of externality. The photographic posture toward things is an imposition of self and tool that typically fails to recognize the constitutive level of that implication. Rather, as a photographer, I believe that that which is evidently "out there," separate from me and unrelated to me or to my approach, is now duplicated by an image, recorded. The imposition so denied is one that makes "having an experience identical with making a photograph of it” (Sontag, 1977, p. 24). As a habituated posture, photographing knows only its own way of living, a particular aestheticizing, passivating, and disengaged from of exteriority. (Shapiro, 1985, p. 28)

Photography as an objective tool for providing evidence of the existence of things is not supported by Hüsserl's (1960) definition of evidence either. "Evidence is, in an extremely broad sense, an 'experiencing' of something that is, and is thus; it is precisely a mental seeing of something itself” (p. 52). In order for the seeing subject or the transcendental ego to experience something however, he or she must be abstracted from the world, "not aiming confusedly at 
something, with an empty expectant intention, but being with it itself, viewing, seeing, having insight into, it itself” (p. 93). Both Ziller and Smith (1977) and Shapiro (1985) position photography on one or the other side of the immanence-transcendence divide (Sjöholm, 2000) that has troubled philosophical inquirers generally and phenomenologists in particular. Each positioning implies a division between the embodied and the known that both Merleau-Ponty (1968) and later Irigaray (1992) contest. By focusing on the photograph as an evidentiary artifact to the exclusion of the photographic performances of subject, photographer, and viewer, Ziller and Smith as well as Shapiro lock themselves into the narrowing consideration of "a photograph as truthful representation." More broadly considered, the photographic performance can be understood as a disturbance that resonates between participants. Fully understood, drawing with light invites viewers and photographers to engage the optical and the tactile in the context of meaningful experience without consolidating each into the other. As explored in Oliver's (2001) response to Vasseleau's (1998) reading of Merleau-Ponty and Irigaray,

If vision involves touching light, then we are touched by and touching everything around us even as we see the distance between ourselves and the world or other people in the world. The texture or fabric of vision is even more tightly woven than Merleau-Ponty's reversible flesh. It is not just that the fabric of vision is reversible between subject and object, invisible and visible, ideal and material; rather the texture of vision is the result of an interweaving of elements both distinct and intimately connected in their sensuous contact. The texture of light is what is between us and other people in the world. We are both connected and made distinct by the texture of light that wraps us in the luxury and excesses of the world. (p. 107)

In his discussion of photography in the 21st century, Flusser (2000) traces a three-millennial shift in the social construction of meaning. Flusser describes each age as committing to conventions of meaning. He sees these as moving from a stage of contestation, through entrenchment, into a stage that he describes as "magical thinking” (p. 8). From Flusser's perspective, the social contestation of meaning is vital; when the meaning of a convention slips into the realm of faith, it poses a vital problem. He focuses on the "technical image" (p. 13), with its blending of the spectacle (from a still earlier millennium) and the technical, as an important response to what he has described as the "textolatry" (p. 85). By linking to, but also calling into question the code, distribution, and accessibility of language as well as the presence, openendedness, and touch of embodied experience, digital images as part of the photographic process represent an important site for renewing the contestation of meaning.

Photography, then, is interesting because its imperfection makes us conscious of both seeing and not seeing, of touching and not touching. What is framed out in the performance of photography is at least as interesting as what is framed in. However, more significant still is the littoral in-between space that serves as a constant reminder of the excess of experience, or the more for both the photographer and the viewer of a photograph. It is the promise of experience hindered by the need to negotiate the grammar of the frame that places a photograph somewhere between language and experience. Like an intertidal zone, the photographic process sheds compellingly incomplete artifacts that draw the subject, photographer, and viewer into an embodied exchange. It is in this experience of exchange that the phenomenological richness of the photographic process resides. 
We have argued elsewhere (Kirova \& Emme, 2006) that photographic seeing is similar to phenomenological seeing, in that it involves "the art of showing" by drawing light onto a given object. It is the photographer's relational orientation to a given object, or a phenomenon that allows him or her to be in touch with it, and thus to evoke an embodied understanding in the reader or viewer. Thus, the notion of an image or a photograph as a visual representation of truth is no longer tolerable, and it is now replaced by a new sense of the place of visuality in meaning (Levin, 1985; Rose, 2001; Stafford, 1996).

Nevertheless, does this photographic/phenomenological seeing apply to one's own body? Unlike all other objects, my body is "something I live, and only secondary know" (Moss, 1989, p. 68, emphasis in original). However, my body is not fully accessible to my perception, as I do not see my whole body. I have an image of my body, but it is not a matter of reflective knowledge of my body that I acquire. As Merleau-Ponty (1963) explains, before reflecting about the body, one already has familiarity with one's body that is acquired at the pre-reflective level. The process of knowing one's body begins in childhood when children reflectively appropriate their body images during the "mirror stage" (Merleau-Ponty, 1962, 1963) by recognizing, labelling, and owning it in the context of close relationships with their families. In this context, the child acquires the physical image of his or her own body through "seeing him- or herself in the others' eyes” (Moss, 1989, p. 67). The ability to recognize himself or herself in the mirror, and the experience of being recognized and identified by his or her family supports the child's formation of a solid body image and identity.

Wawrzycka's (1995) analysis of Barthes (1981) describes a focus on the concept of punctum, the sharp point or prick of recognition that touches us when we look at some photographs in which we can find:

the genius of Photography and its horror: a photograph simultaneously testifies to the presence of a thing at a certain past moment and to its absolute pastness, its death. By attesting that what we see had indeed existed, Photography partakes in the economy of "Death and Resurrection." (p. 94)

Looking at an image of one's self as part of the photographic process makes both the space and the vitality between self and sign explicit. In extending Barthes' (1981) thinking to children's participation in phenomenological inquiry through fotonovela described below, our focus was on sensitivity to the child's sense of embodied recognition as experienced through a combination of tableau, photography, and digital manipulation. These significant layers of playful inquiry became an opportunity for the children to discover stories in their experience and create a hybrid language of image, body, and sometimes word for that story.

\section{Returning to the Phenomenon: Engaging the Body}

In order to show a phenomenon as lived, a phenomenologically oriented researcher gathers experiential accounts from individuals who have experienced the phenomenon of interest, or accesses participants' written descriptions or even fictional narrative. Gathering relevant experiential accounts is only the first step toward describing the structure of the phenomenon, as others can understand it. "It is best to think of the basic method of phenomenology as the taking up a certain attitude and practicing attentive awareness to the things of the world as we live them 
rather than as we conceptualize them" (van Manen, 2000, p. 460). This attitude indicates a relation, an orientation to the phenomenon that allows a return to things as lived. The return to things that phenomenologists of all schools call for involves accessing the phenomenon, being in touch with it.

When I take part in the phenomenon that I am seeking to understand and show, I am not simply taking on what is simply given in it. Instead, as Shapiro (1985) explains, in "one moment of the same act, I impart to it. My participation is coconstitutive of the moment, situation, or phenomenon” (p. 36). Of a particular interest to the method presented below is Shapiro's explanation of the coconstitutive reentry and the role the abstractive act-for example, in phenomenological descriptions of the structure of phenomena-as "an embodied act that participate[s] in the immediate engaged moment of lived experience” (p. 31). As part of a phenomenologically oriented method that we called fotonovela, we invited the immigrant children with whom we were working to select "telling moments" of their experiences of their first day in school, and enact them as tableau that eventually became images. In this case, a fotonovela was a form of storytelling that combined the familiar framing devices, sequencing, and text balloons of the comic book with posed or candid photographs of the participants in place of pen-and-ink sketches, which we have described elsewhere (Kirova \& Emme, 2006; Emme \& Kirova, 2005). Whereas performance is generally accepted as a means that allows participants to depict and examine their real-life "performances," thus "providing insight into their lived experiences and their cultural world" (Conrad, 2004, p. 10), we explored enactment-a performance of tableau - both as a form of reliving the phenomenon of the first day at school in a new country, and as an abstractive act that originated in the relived phenomenon.

According to Shapiro (1985), the task of the phenomenologist is to make the "implicit structure of a phenomenon explicit by enacting it” (p. 140). For him, enactment is possible through reflection as a bodily mode that involves both the virtual feel of the bodily experience of the phenomenon and virtual conduct that leads to apprehension of the structure of the phenomenon achieved through a mode of abstraction. Shapiro refers to this virtual experience as forming.

Forming is a virtual rather than an actual behavior, and its enactment occurs in abstract rather than a concrete space.... [However,] forming does not occur in the mind's eye. It is a bodily mode, a kind of doing, a virtual movement, not a species of imagination. (p. 134)

In the development of the fotonovela as a phenomenologically oriented research method, we considered children both as participants and as coresearchers; they were to provide the experiential accounts as well as create (visual) texts that captured the structure of their lived experiences of the first day in school. In other words, we intended the method to gain access to immigrant children's experiences in general — and their first day of school in particular-in a way that was not restricted to the English language. This arose as a special concern due to some of the children's limited proficiency, and because as researchers we did not share a common language with most of the children (Kirova \& Emme, 2006). At the same time, we intended the method to help children reflect on their lived experiences, share these experiences among themselves in the process of performance, and, finally, share their experience with a new group of children/readers as a visual narrative based on a performance. We argue that the children's unique position in the process of inquiry allowed us to conceive enactment in a more literal sense 
than those described by Shapiro (1985). In fact, the conceptualization of enactment that we employed in the development of fotonovela as a research method was closer to Merleau-Ponty's (1962) and van den Berg's (1955) notions of engaging in a return to the phenomenon by “inhabiting” it or "being” in it.

\section{Enacting "Being at the Door"}

In reference to a point by Shapiro (1985) cited above about the role of situations in inviting a particular body action, we clarify here that we consider the structure of a school building itself as able to create a particular type of situation. Like a cathedral or any other public building, a school building is "a living body" (p. 115) that represents special kinds of relationships which require certain types of behaviors. Although the living relations that a school building embodies are implicitly present in everything experienced in it, it is impossible to know what the experiences are before one lives them. For example, encountering the relationships embodied in the dynamics between hallway and classroom, and the varied behaviors expected by a child while in each, can be a challenge for a refugee or immigrant child who has not experienced being in a school building. This does not mean that children lose a sense of their body as a vehicle for action - that is, a vehicle for relating to the physical world of objects through the body. Rather, the lived moment of being at the door of a classroom for the first time in an unfamiliar school building is one that invites a body action that is far from habitual and thus brings the body to the child's consciousness. Our work with the participating immigrant and refugee children over two years (Kirova \& Emme, 2006) pointed to the importance of this moment in children's recollections of their first day of school. Yet the children knew more about that particular lived moment than they could tell. By inviting them to relive the phenomenon through a re-enactment of the moment of being at the door of their new classroom, we hoped that the children's bodies would remember their original experiences. We also hoped that through this enactment, they would be able to abstract some commonalities from their individual experiences, and that these would represent certain general aspects of the structure of the phenomenon that we were attempting to show.

The actual performance or act of reliving the experience of being at the door of an unknown classroom took place in the participating children's home classroom, where we offered them photographic experiences as members of the photo club. We asked the children to remember the first day of school and the moment when they came to the door of the classroom. The following questions facilitated the children's recollection of that particular moment. Were you by yourself? If not, who came with you? Was the door open? What was the first thing you remember seeing? Were there other people in the classroom, and what were they doing?

It is worth noting here that while children were bodily engaged in enacting their past experiences of being at the classroom's door, they also had the task of reflecting bodily on the experience by selecting a "telling moment," a moment that is intended to show the essence of this particular moment as they (individually) lived it. This selection of a telling moment, in turn, allowed the moment to be photographed as tableau — as "a still, silent performance that involves three dimensional representation” (Wilson, 2003, p. 375). A further description of tableau as a still image in structuring drama work clarifies that in the process, either "groups devise an image using their own bodies to crystallize a moment, idea, or theme, or an individual acts as sculptor to a group” (Neelands, 1998, p. 19). We used both the above approaches in our particular case. 
As a group, the children participated bodily in the development of the moment of being at the door, and each child acted as a "sculptor" of the group, shaping his or her particular individual experience, including the assignment of roles to each of us. Thus enactment-as an element of the phenomenologically oriented fotonovela method-allowed the children both to reside bodily in the lived moment (as a return to the phenomenon) and to distance themselves from it (as an abstractive act, enabling reflection on the structure of the phenomenon). In the process, however, we did not lose sight of the fact that we were working with young children and that we needed to maintain the playful nature of performance if we wanted the children to participate in the process.

\section{Creating Visual Text}

Comic book artist and visual theorist McCloud (1994) articulated many of the formal qualities of what Eisner (1985) called "sequential art" (cited in McCloud, 1994, p. 5). In discussing the invitation to meaning in images as they are affected by framing and text layered together, particularly when such images are sequenced with others, McCloud describes an enormously complex and flexible resource. A gesture as simple as putting two images beside each other, or changing a speech bubble to a thought bubble, can fundamentally shift the meaning. As described elsewhere (Emme, Kirova, \& Cambre, 2006; Kirova \& Emme, 2008), we offered immigrant children a variety of approaches to fotonovela as a way of playfully embodying their experiences as new students in a Canadian school. With children engaged in building fotonovela, the photographic and tableau processes described above were sequenced and adjusted by each child. Whether self-consciously edited or incorporated into playful creation, the visual elements were susceptible to any embodied nuance that the children brought to their engagement.

Shapiro (1985) defines a phenomenon as "the theme in the variations on a theme" (p. 53). In looking at these images from a phenomenological point of view, we suggest that they show more than variable appearances of the phenomenon; we gain a feel of the phenomenon. This general feel of the phenomenon, known as texture, is what affects the reader bodily and is recognized by the reader as a plausible (human) experience. "Every phenomenon intends a world ... [that] has a general atmosphere or ambience or tone or style or way or physiognomy” (p. 53). In this sense, it is the texture that allows the reader to enact the phenomenon in the virtual, empathic sense indicated by Dilthey (as cited in Todres, 2007) and Shapiro. We suggest that the use of fotonovela, both as a performance of the lived experience and as a process of creating an image of that experience, allowed for a richer description of the phenomenon than could have been accomplished by relying on children's oral recollections alone. However, although the structure of the phenomenon of being at the door of a new classroom may be less explicit in the visual texts presented, which may in fact be enhanced by the use of language, the texture or feel of the phenomenon is communicated fully by the visual texts. Singly, and as a varied group, these nuanced choices by the children have texture. 


\section{Writing the Text/Reading the Text: The Role of Language}

While looking at the visual texts presented below, a phenomenologist may ask: Are they sufficiently descriptive of the phenomenon of being at the door of a new classroom? All of the children worked hard to "sculpt" the moment as they lived it, and yet do we have a sense of what they were thinking or feeling as they stopped at the door and looked in, or derived enough courage from their mother's hand on their shoulder to walk into the classroom? The structure of the building (the hallways on each floor with doors to separate rooms), as well as the situation (being in that school for the first time), invited a particular body response presented in each image. However, can we tell by looking at the images how children's previous experiences coloured that lived moment? "My body can carry the significance of an earlier moment and in that my behavior can find similarities in different objects, through them I can embody, enact, and in those cases, express metaphors" (Shapiro, 1985, p. 157). If metaphor is a "carrying over of the sense or meaning of one reality to another" (Romanyshyn, as cited in Shapiro, p, 157) then language in the form of metaphor, or another figure of speech, is a necessary step in the journey toward returning to the phenomenon as lived. However, as Todres (2007) puts it, "Even though language and experience are implicated in one another, they cannot be reduced to one another nor replace one another in the ongoing aliveness that is understanding” (p. 23). He further explains that they "both require one another as partners in a conversation, and both phases (embodying and languaging) constitute both limits and freedom in this conversation” (p. 34).

In the development of fotonovela as a research method, our next step was to ask the children to insert in their photograph a thought balloon-a common device used in comic books to indicate what a character is thinking - that captured their overall feeling as they were at the door of the new classroom. This is what the five children wrote; the children's words and punctuation are presented verbatim.

- Ooooo......!!! They stare at me to death!!! I want to go HOME!!

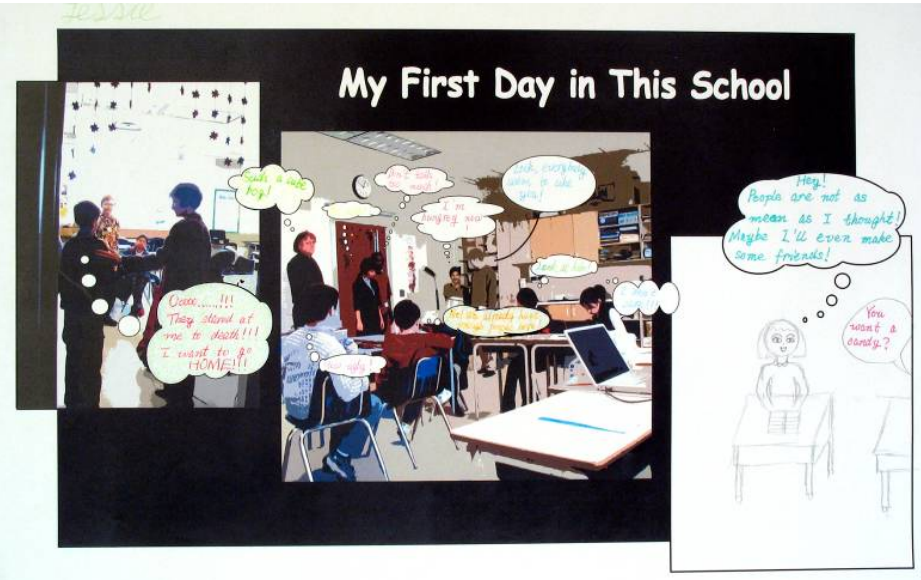


- Don't hit me teacher!

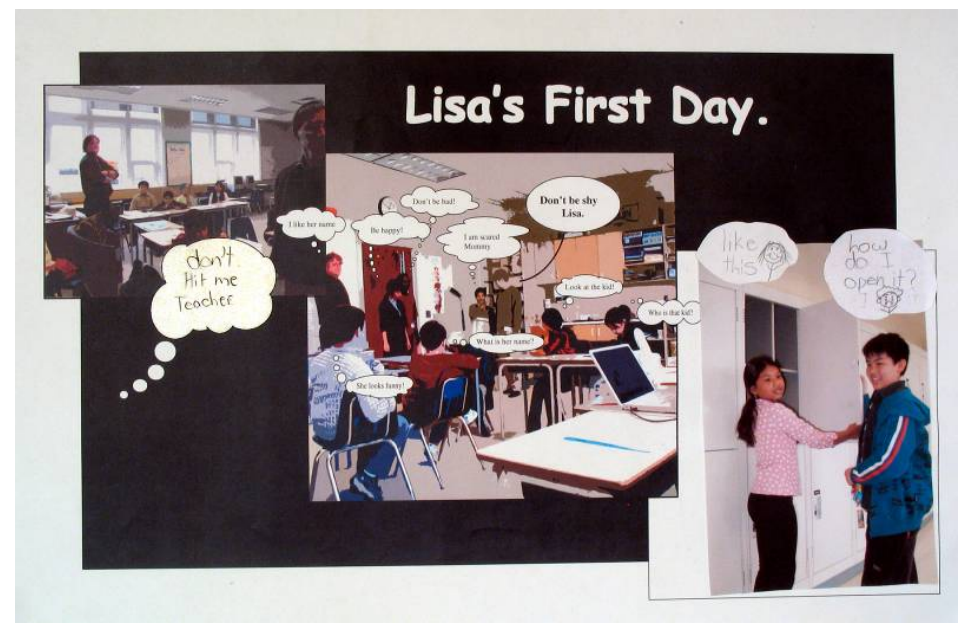

- Uh oh! What are these people like? What if they laugh at me that I don’t know English?!

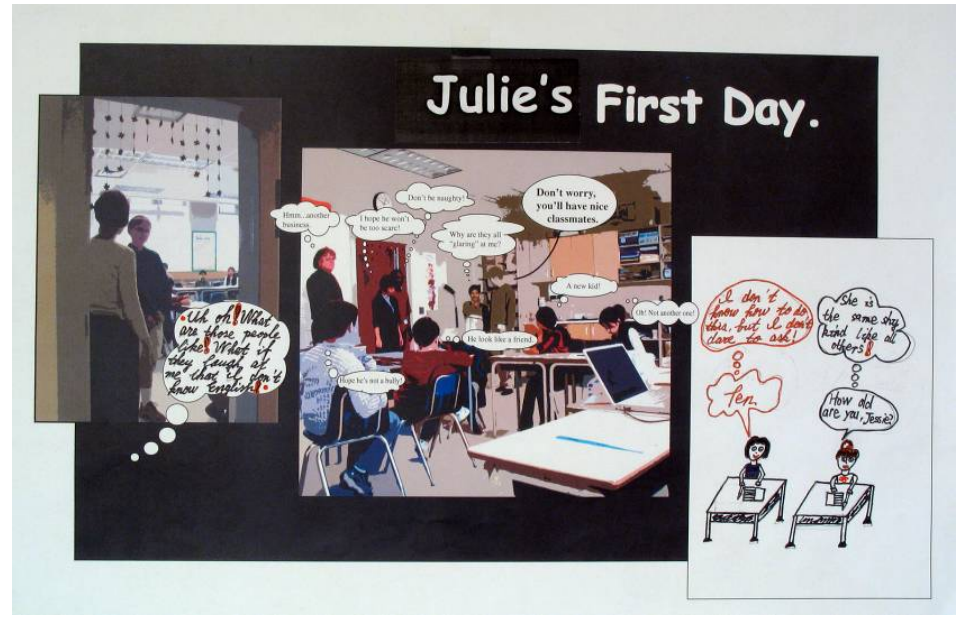

- What scary people. Why they [sic] staring at me. I am so nervous. Don't make fun of me people.

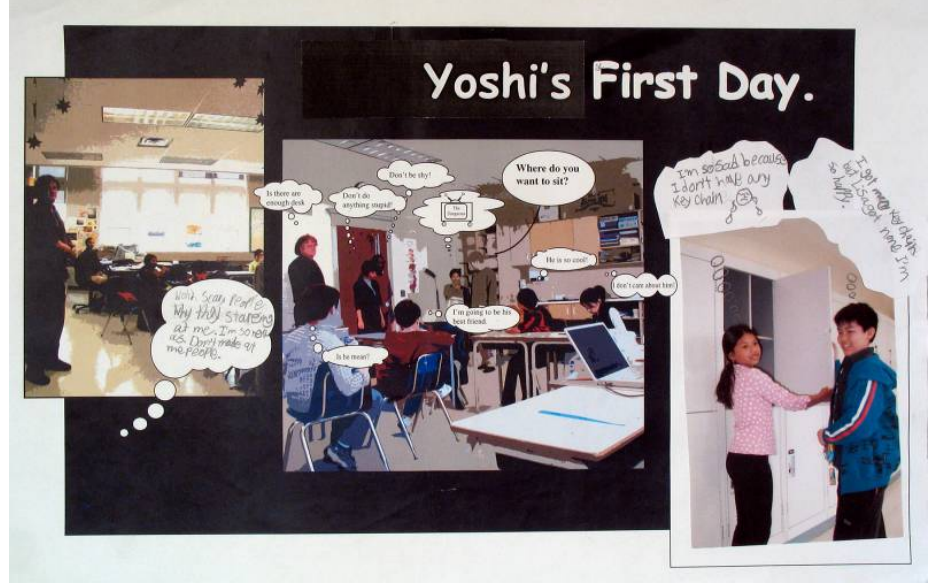


- What can I do from today?

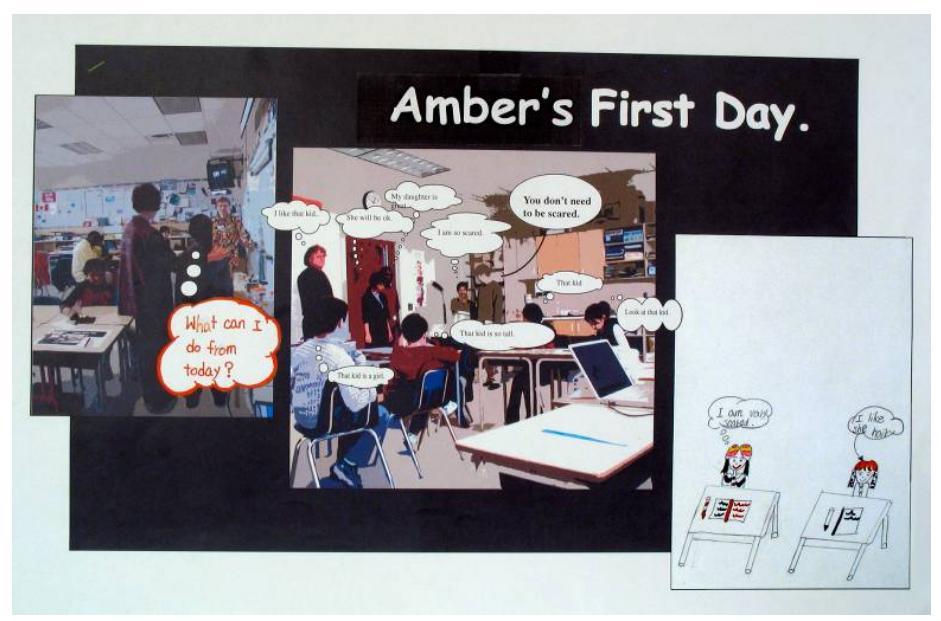

The unsaid in the Heideggerian sense is always more in the Gendlinian sense than the said. Yet as the above examples of the said show, the said has the power to give meaning or even change the more. Although the implicit remains in the unsaid (in our case the visual), the said allows itself to be thematized and is thus given meaning through language. However, we argue that it is the combination of the two that presents the lived moment of being at the door as a whole.

Along with the overall feeling of fear and uncertainty, in this case the said revealed the children's bodily awareness as they felt others looking at them and were fearful of being laughed at because of their English. In fact, the lived sense of being looked at was so dominant in the next experiential moment that all the children agreed to have one central photograph representing the moment when they were in the classroom and everyone stopped their work to look at the new kid (Kirova \& Emme, 2006). For the purposes of this article, however, we focus only on the first frame of the three-frame fotonovela. 


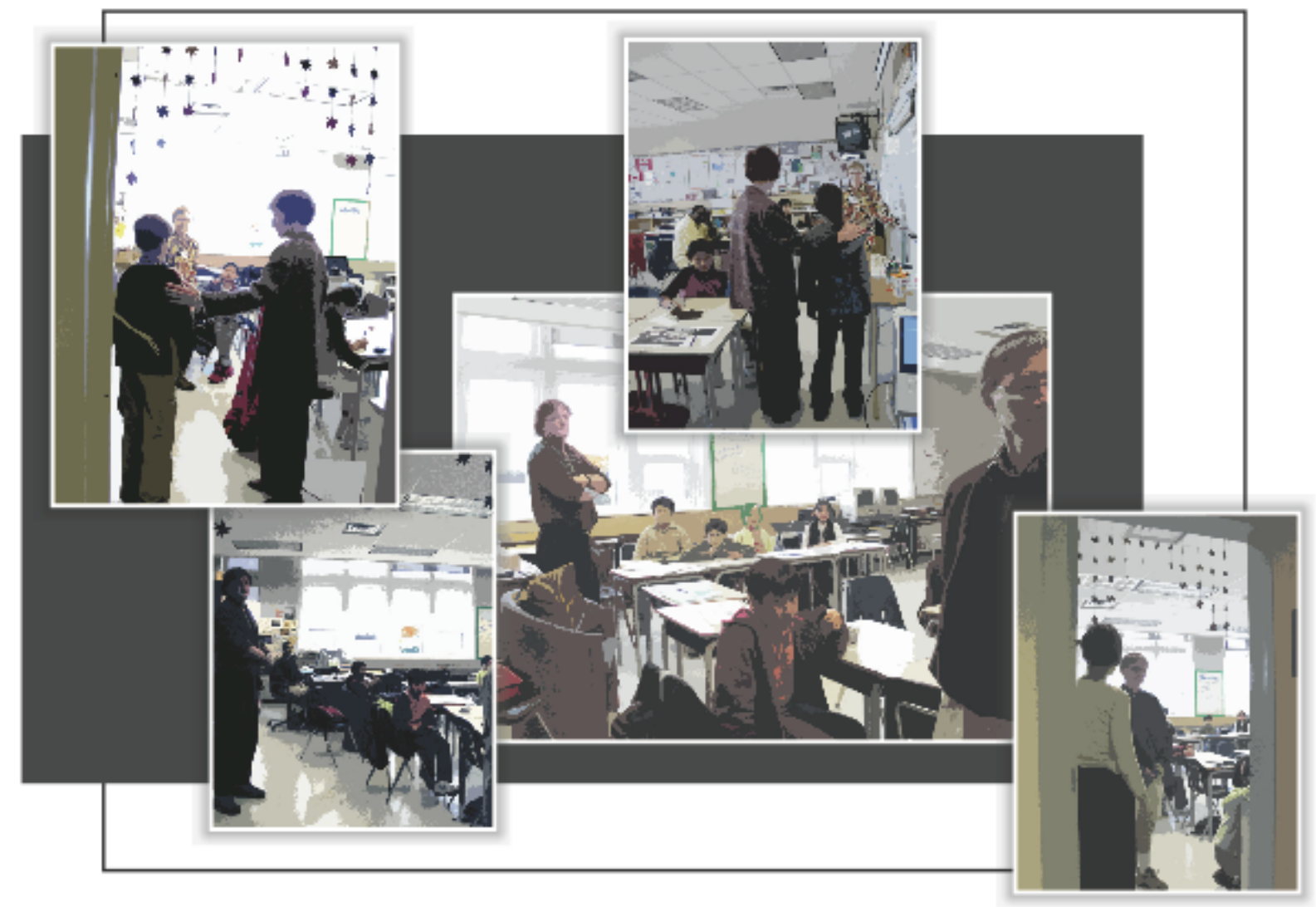

We argue that fotonovela both as a process and as a product creates a space for a new relationship between the visual and the linguistic that enables us to artfully capture the phenomenon of being at the door of a new school. We wondered, however, if readers could feel the phenomenon, and if the visual was the only aspect of the description of the phenomenon to which they would have access. To elicit responses from readers, we gave one version of the three-frame fotonovela to 14 Grade 5 children who were not part of the performance of the tableau or the production of the fotonovelas. Twelve of these children were themselves firstgeneration immigrants to the country, and some had recently arrived from their countries of origin. The children were given the fotonovela with the first two frames titled "My First Day in this School” and a sheet of blank speech/thought balloons to cut out and glue onto the pictures as they saw as appropriate to the story. 


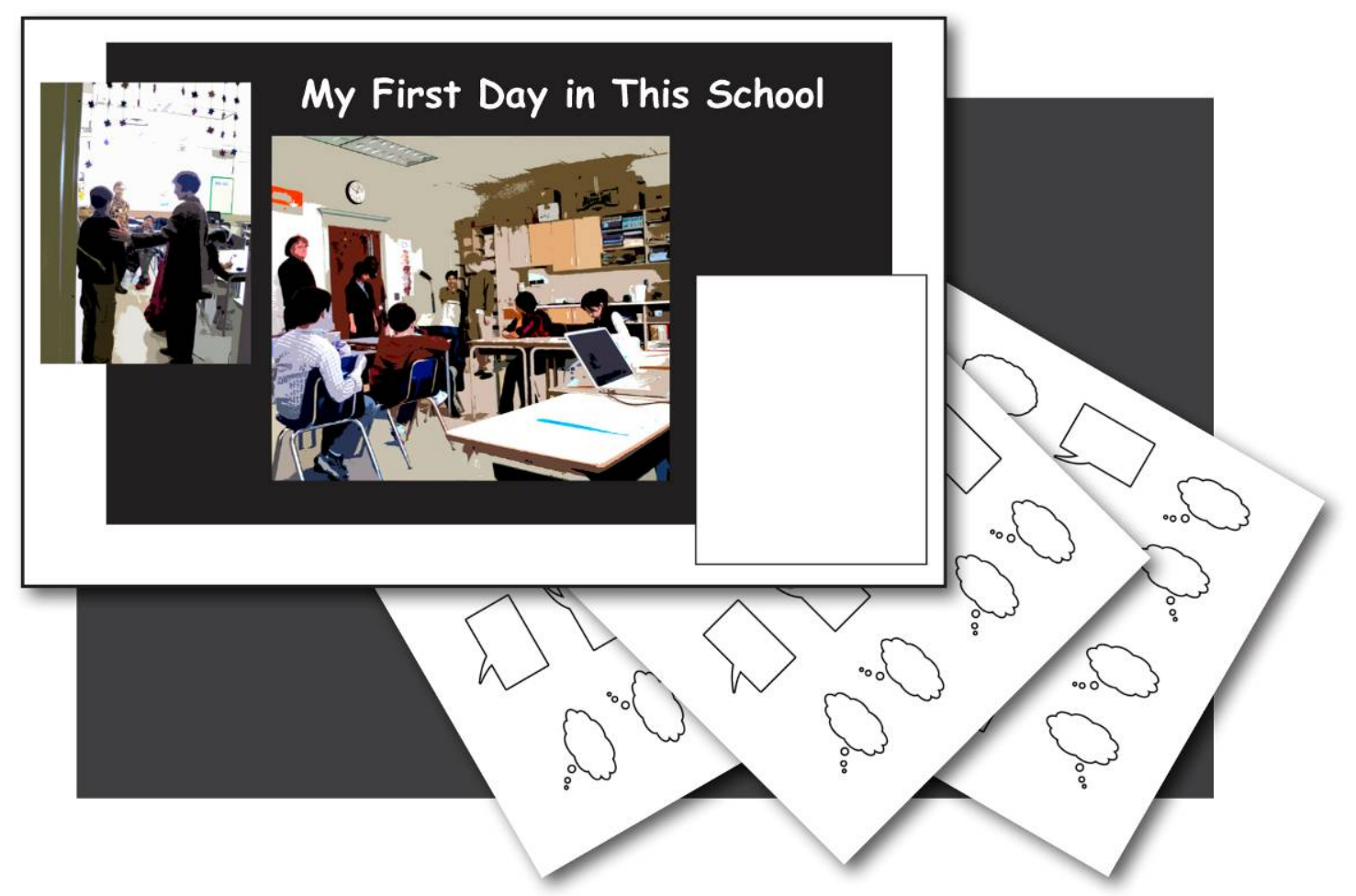

The last frame was left blank so that the children could personalize the story in accordance with their own experiences of the first day in school. They could choose either to take a photograph or to draw a picture of what happened when they were introduced to the class.

Most of the children related to the visual text as intended by its authors. The following are these children's responses to the first frame of the fotonovela, the one addressing the experience of being at the door.

- I am scared. (two children)

- I am scared. What if they make fun of me?

- This class looks dangerous.

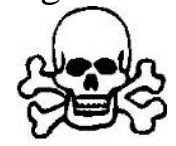

- Uh! Oh! I am gona [sic] die!

- I think that I am going to faint!

- What if they don't like me?

- I think that I am going to pee my pants.

- I am really shy.

Other children expressed less fear of the unknown "hiding" behind the door of the classroom and were even optimistic about what they encountered. These are their responses:

- I am shy. Wonder if I don’t get any friends but now I know I will.

- Holly [sic] that's a lot of kids. Maybe I can say hello my name is Michelle.

- Well this looks fun.

- Today is my first day I am happy. 
- C’mon be nice at least say "hi” to your new classmates. Gulp! (clears throat)

Based on the work of Ricoeur (1987), we have argued elsewhere that the reader/viewer is the imaginary me created by art as a playful representation of a world (Emme \& Kirova, in press). "It is a question of entering into an alien work, of divesting oneself of the earlier 'me' in order to receive, as in play, the self conferred by the work itself” (Ricoeur, 1987, p. 190). In viewing or reading photography, the meanings intended by the image-maker and those envisaged by the viewer partly converge in their shared experience of the photograph. By emphasizing playfulness in both the production of the visual narratives and their reading/viewing by readers, we wish to emphasize that there is no representational truth in either the visual or the linguistic descriptions of the phenomenon, and so there is always a complex sense-making of the lived experiences based on the tension between languaging and embodying. As we demonstrate here, the “phenomenological nod" is a result of readers' engagement in their own experiences of the phenomenon as shown through words in the text. Thus, we suggest that a visual narrative as in fotonovelas has similar evocative power.

\section{Discussion}

In this article, we explore the role of the lived body in meaningful understanding beyond linguistic conceptualization in phenomenologically oriented inquiries through the question, what methods of inquiry can be used to access more directly the "embodied understanding" and, in particular, the lifeworlds of immigrant children as they leave the familiar "home world" and enter the "alien world" of a new school? We believe that the phenomenologically oriented method that we call fotonovela provided an example of how the process of engaging the body and visuality in the process of phenomenological inquiry provided space for the immigrant children who participated in the project to recall and relive his or her experiences of being at the door of a new classroom and to reflect on it. In this sense, it enabled these children "to cast back light, to give back or show an image” (Random House Webster Dictionary, 1990, p. 1132), and to share this experience with others in a format that had the evocative power similar to that of a phenomenological text. We have argued elsewhere that as a research method characterized by collaboration between researchers and participants, fotonovela "changes both the way of seeing and readers' self-understanding” (Kirova \& Emme, 2008, p. 52), and thus it is qualitatively different from other methods employed in research with children that are still "prompted, designed, analyzed and disseminated by adults" (Greene \& Hill, 2005, p. 12). In this particular article, we extend these arguments even further by explicating the contributions of our method to accessing and understanding embodied experiences and the complex relationships between body, language, and image in this understanding. The notion that there is more to the experience than can be captured by language-based descriptions inspired our exploration of the possibilities offered by arts-based research methods-performative and visual arts - in developing a collage method of inquiry (Kirova \& Emme, 2006). This method is one that invited young children to be fully included in the process of making meaning of their lived experiences, and it simultaneously affirmed the embodied nature of understanding. We suggest here that the method discussed in this article and elsewhere does not favor image over text or body over language. Rather, we argue that by exploring the complex interplay of all of the above, what is described elsewhere as "poly-media" (Emme \& Kirova, in press), adds to the ongoing conversation in the human 
sciences about the questioning of "what it means to know." We believe that the examples of children's exploration of their fotonovelas depicting the first day of school and our discussion of this process demonstrate that we see knowing as understanding that is non-consensual, ever evolving, and relational. We also believe that these examples show how the knowledge children gain through such a process of understanding can be shared in a multimodal text that evokes, in turn, embodied responses as part of children-as-readers' understanding. From this perspective the fundamental ethical question in research, “Knowledge for whom?” takes on a new meaning.

\section{Endnotes}

\footnotetext{
1،Poly-Media" is a term chosen to create a distinction from "Multi-Media". As described by Alsop (2007), polymedia art making is considered as a collaborative system in which all collaborators, such as composers, video artists, choreographers, actors and writers contribute to the final product by interacting collaboratively throughout the development process to the eventual presentation of the work. This system is distinct from a "multi-media" approach where the different aspects may be developed independently and then marshaled towards the end of the development process.
}

\section{References}

Alsop, R. (2007). Compositional Processes in Developing Poly-Media Performance Works. Retrieved from http://people.smartchat.net.au/ rogeralsop/Compositional_Processes_R_Alsop.doc []

Barthes, R. (1981). Camera lucida: Reflections on photography (R. Howard, Trans.). New York: Hill \& Wang.

Bruner, J. S. (1986). Actual minds, possible worlds. Cambridge, MA: Harvard University Press.

Chan-fai, C. (2004). Separation and connection: Phenomenology of door and window. In D. Carr \& C. Chan-fai (Eds.), Space, time, and culture (pp. 253-262). Dordrecht: Kluwer Academic.

Conrad, D. (2004). Exploring risky youth experiences: Popular theatre as a participatory, performative research method. International Journal of Qualitative Methods, 3(1). Retrieved from http://www.ualberta.ca/ iiqm

Eisner, W. (1985). Comics and sequential art. Principles and practices of the world's most popular artform. Tamarac, FL: Poorhouse Press.

Emme, M., \& Kirova, A. (2005). Fotonovela. Canadian Art Teacher, 4(1), 24-27.

Emme, M, Kirova, A., \& Cambre, C. (2006). Fotonovela and collaborative storytelling: Researching the spaces between image, text and body. Exposure, 39(2), 45-51. 
Emme, M., \& Kirova. A. (in press). Body/image/text: Fotonovela, digital technology and polymedia narrative. In C. Mullen \& S. Steinberg (Eds.), Viewfinding. New York, NY: Peter Lang.

Emme, M., Kirova, A., Kamau, O., \& Kosanovich, S. (2006). Ensemble research: A means for immigrant children to explore peer relationships through fotonovela. Alberta Journal of Educational Research, Theme Issue: Researching With Children and Youth, 52, 160-182.

Flusser, V. (2000). Towards a philosophy of photography (A. Matthews, Trans.). Suffolk, England: Reaktion Books.

Foucault, Michel. (1983). This is not a pipe. With illustrations and letters by René Magritte (J. Harkness, Trans. \& Ed.). Berkeley: University of California Press.

Gadamer, H.-G. (1993). Truth and method (2nd ed.). (J. Weinsheimer \& D. G. Marshal, Trans.). New York: Continuum.

Gendlin, E. T. (1997a). Experiencing and the creation of meaning. Evanston, Springfield, IL: Northwestern University Press.

Gendlin, E. T. (1997b). How philosophy cannot appeal to reason and how it can. In D. M. Levin (Ed.), Language beyond postmodernism: Saying and thinking in Gendlin's philosophy (pp. 3-41). Evanston, IL: Northwestern University Press.

Greene, S., \& Hill, M. (2005). Researching children’s experiences: Methods and methodological issues. In S. Greene \& D. Hogan (Eds.), Researching children's experiences: Approaches and methods (pp. 1-21). Thousand Oaks, CA: Sage.

Hüsserl, E. (1960). Cartesian meditations (D. Cairns, Trans.). The Hague: Nijhoff.

Irigaray, L. (1992). Elemental passions (J. Collie \& J. Still, Eds.). London: Athlone Press.

Kirova, A. (2001). Loneliness in immigrant children: Implications for classroom practice. Childhood Education, 77(5), 260-268.

Kirova, A., \& Emme, M. (2006). Using photography as a means of phenomenological seeing: "Doing phenomenology" with immigrant children. Indo-Pacific Journal of Phenomenology Special Edition: Methodology, 6(1).1-12. Retrieved from http://www.ipjp.org

Kirova, A., \& Emme, M. (2008). Fotonovela as a research tool in image-based participatory research with immigrant children. International Journal for Qualitative Methodologies, $7(2), 35-57$.

Levin, D. M. (1985) The body's recollection of being: Phenomenological psychology and the deconstruction of nihilism. London: Routledge \& Kegan Paul. 
Levin, D. M. (1990). The body's recollection of being. London: Routledge \& Kegan Paul.

McCloud, S. (1994). Understanding comics: The invisible art. New York: Harper.

Merleau-Ponty, M. (1962). Phenomenology of perception. London: Routledge \& Kegan Paul.

Merleau-Ponty, M. (1963). The structure of behavior. Boston, MA: Beacon Press.

Merleau-Ponty, M. (1968). The visible and the invisible (A. Lingis, Ed.). Evanston, IL: Northwestern University Press.

Moss, D. (1989). Brain, body, and world: Body image and the psychology of the body. In R. S. Valle \& S. Halling (Eds.), Existential-phenomenological perspectives in psychology: Exploring the breadth of human experience (pp. 63-82). New York: Plenum Press.

Neelands, J. (Ed.). (1998). Structuring drama work: A handbook of available forms in theatre and drama. Cambridge, UK: Cambridge University Press.

Oliver, K. (2001). Review of textures of light. Hypatia, 16(1), 106-108. Retrieved from http://muse.jhu.edu/journals/hypatia [10.11.09]

Random House Webster's College Dictionary (1995). New York: Random House.

Reed, D. I. (1987). An empirical phenomenological approach to dream research. In F. van Zuuren, F. J. Wertz, \& B. Mook (Eds.), Advances in qualitative psychology (pp. 96-116). Berwyn, PA: Sweet and Zeitlinger.

Ricoeur, P. (1987). Hermeneutics and the human sciences. Cambridge, UK: Cambridge University Press.

Rose, G. (2001). Visual methodologies: An introduction to the interpretation of visual materials. Thousand Oaks, CA: Sage.

Salvio, P. M. (1990). The world, the text, and the reader. In A. A. Lunsford, H. Moglen, \& J. Slevin (Eds.), The right to literacy (pp. 269-275). New York: Modern Language Association.

Shapiro, K. J. (1985). Bodily reflective modes: A phenomenological method for psychology. Durham, NC: Duke UP.

Sjöholm, C. (2000). Crossing lovers: Luce Irigaray’s elemental passions. Hypatia, 15(3), 92-112.

Sontag, S. (1977). On photography. New York: Farrar, Straus \& Giroux.

Stafford, B. (1996). Good looking: Essays on the virtue of images. Cambridge, Massachussetts: MIT Press. 
Steinbock, A. (1995). Home and beyond: Generative phenomenology after Husserl. Evanston, IL: Northwestern University Press.

Todres, L. (2007). Embodied enquiry: Phenomenological touchstones for research, psychotherapy and spirituality. New York: Palgrave Macmillan.

Van den Berg, J. H. (1955). The Phenomenological Approach to Psychiatry. IL: Charles C. Thomas.

Van Manen, M. (1994). Researching lived experience: Human science for an action sensitive pedagogy. London, ON: The Althouse Press.

Van Manen, M. (2000). Professional practice and 'doing phenomenology.' In S. K. Toombs (Ed.), Handbook of phenomenology and medicine. London: Kluwer Academic Publishers.

Vasseleau, C. (1998). Textures of light: Vision and touch in Irigaray, Levinas and MerleauPonty. Warwick studies in European philosophy. New York: Routledge.

Wagner, B., J. (1998). Educational drama and language arts: What research shows. Portsmouth, NH: Heinemann.

Wawrzycka, J. (1995). Photographeme: Mythologizing in camera lucida. In J. Rabaté (Ed.), Writing the image: After Roland Barthes (pp. 90-99). Philadelphia, PA: University of Pennsylvania Press.

Wilson, P. (2003). Supporting young children's thinking through tableau. Language Arts, 80(5), 375-383.

Ziller, R., C. \& Smith, D., E. (1977). A Phenomenological utilization of photographs. Journal of Phenomenological Psychology, 7(2), 172-182. 